\title{
NATURE AND ART AFTER CORONA, NEW POTENTIALITIES AND FUTURE MISFORTUNES
}

\author{
Dr. Tina Porwal ${ }^{1} ه$ (iD) \\ Co-Founder, Granthaalayah Publications and Printers, India
}

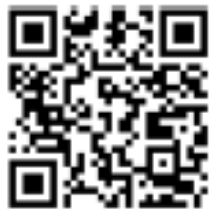

\section{ABSTRACT}

Much has already been written about Covid-19, but now we should get used to living with it because Corona is not going to leave our lives so easily. We should now practice living with it. As soon as the lockdown ends, we have to defend ourselves and our family and at the same time run our business smoothly. Now we should learn how to keep our family away from the corona, and stay unconnected, follow social distance, etc. Now this is our life for some time to come. We have to make ourselves so strong that the corona cannot spoil us. Over time, we will get used to living with it. An artist must also change his mind and accept the coming change.

Keywords: After Corona Nature, Art New Potentialities Future, Misfortunes

Received 02 May 2020

Accepted 16 June 2020

Published 27 June 2020

CorrespondingAuthor

Dr. Tina Porwal,

sethiya.tina@gmail.com

DOI

10.29121/shodhkosh.v1.i1.2020.11

Funding: This research received no specific grant from any funding agency in the public, commercial, or not-for-profit sectors.

Copyright: (C) 2020 The Author(s). This is an open access article distributed under the terms of the Creative Commons Attribution License, which permits unrestricted use, distribution, and reproduction in any medium, provided the original author and source are credited.

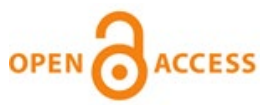

\section{INTRODUCTION}

Today the artist needs to change his thinking. Modern-day artists will have to be 'Google Friendly' because it is difficult to find the same atmosphere as before. By accepting this truth, we must consider new ways of living our lives. The sooner you consider, the sooner you will be able to carry on your business and run your life smoothly.

The artist who is completely free from social harmony will be able to design the way to display his art, that artist will be able to survive in the coming time. The artist today just needs to change his thinking according to the demand of modern times. If the artist thinks about it now, many possibilities will be seen in the future, because this is the only way to stay strong in this era. Vajpeyi (2020)

The artist who will think in a new way will achieve a lot in the future and will be able to beat Corona in the same way and we will not be able to beat corona by fight.

Due to the measures taken by the government so far to avoid this epidemic, the economic condition of all classes has been severely affected and the social situation has also changed a lot. All kinds of activities happening in the group will stop completely for some time now, while we are all Indian social animals, without society we cannot even imagine our life.

In the map of the new society that has just emerged, business activities like construction, production etc. will be restored, but educational institutions, auditorium etc. will remain closed for many months at least because of the 
present situation and dangers. When there is some discount in them, it will be extremely limited grouping.

\section{NEW POTENTIALITIES}

If we look at the situation before the corona epidemic, we will find that the background of fighting this epidemic was already prepared in the society. As the trend of online cinema, only a few artists used to perform in performing arts, online live-show trend was increased, books and literature started to be seen and read online, artists now started expressing their ideas through blogs too. Where, the mainstream media was spreading hatred, the social media was spreading and showing the truth. In the Corona era, now small illnesses have reduced on their own. High levels of deficiency have been observed in the rituals of all religions. During the time of lockdown, people got to take time for themselves and became aware of their importance and existence. The best part is that there was a decrease in pollution everywhere. That is, we can say that in the coming times the society will be conscious and balanced. Gupt (2020)

While the utility, convenience and power of technology is very positive, there are challenges as well or we can also think positively that this will give all artists new skies that they may not have met before, or they have never before I will not even think.

\section{FUTURE MISFORTUNES}

Covid-19 has had a great impact on demonstrative folk arts and fine arts. For example, in the performing arts, the listener or the audience has an important role, but when the arts are not displayed, then how will the artist make a living? It may be that the show is closed for some time, or it starts happening in large groups or parties. There are some advantages as well as disadvantages. The disadvantage is that the means of income of the artist were already limited and now will become even more limited. The advantage will be that the receipts will be more active and visible in the small parties and the other advantage is that there is a lot of nuances in the performing arts which is not often seen in a large auditorium but in small groups, all this is seen. Can be understood and appreciated. Awasthi (2020)

Just as there is a danger of loss of livelihood from online performance, there is also a problem that when the presenter and the audience will not be directly faceto-face, the amount or items which the presenter would have received after the presentation as gift form or training, will not meet. We must find solutions to all these problems ourselves.

There is also a problem that how should an artist live till a certain system is developed? Because the artist gets a remuneration, his life depends on it. Now if there is no solution to it, then how will the artist live for at least some time? Those who teach in small towns or in small places in cities, how will they impart training or learn from a distance? The biggest problem will be for folk artists because these arts depend only on community. Ministry of culture (2020) But when society will have nothing to give, then how will they make these folk arts magnified? If the performance of all the arts starts online then a problem will come that no person will go out to the auditorium (even after the end of the lockdown) to listen to music, dance, etc. When he gets to see everyone at home, then why would he waste his 
precious time by going out? Online also has its own dangers as it will or has become a tool to destroy liveliness which would be very unfortunate. Yajnik (2020)

The artist should not just rely on the government. but can inspire the government in this era, the role of society is positive but politics changes odd. In contemporary times, both art and life of artists are in danger. It is a question of the existence and death of art.

\section{CONCLUSION}

There are some confusions also with today's circumstances. Like we had made the impression that we are the happiest generation. We can also consider this time (lockdown) as an opportunity or consider it a challenge. In such times, art and culture can also play a very big role. This mental fear will have to come out spiritually, from a panic-filled environment or from a crisis. Tradition can be increased by knowledge and can be taken out from this time. In such times, art, artist, culture, and the lives of the great men who brought it into their lives are supported and will be found and the future will be found. This time the artist should not get into controversies like how this crisis came, is a big conspiracy or is nature given? The artist must face challenges and get out of challenges meaningfully.

Today, artists should not seek strength in controversies, today the need is to answer and find out. In the answer where there will be dialogue, peace, harmony, love and compassion, the answer will be able to give solution. The need is there today, and it is in the art of strength.

The concern about literature and art is bound to be expressed but it has become mandatory to avoid grouping. The solution to this problem is to make a big 'Kosh'. Vajpeyi (2020) Ashok Vajpayee says that musicians, dancers, sculptors in this large treasury have more means to live and help in the beginning. Then help should be taken from the government and the corporate world.

According to me the government should take steps towards making artists aware of modern techniques. For this, the government should make amendments in the ongoing art courses. Shortly before today when I am M.F.A. In then, the government added some important topics of visual arts syllabus, such as seminar projects, short research etc. Even today, this amendment is needed. The Indian government today is poised to create a 'self-reliant India', but artists need to ask the government how it will make artists self-reliant. For this, the artist must also become responsible citizen and follow the rules made by the government.

Today, science has spread its legs all over the world through technology, just like we can see the entire display in 360-degree view. This technique has started to be used in foreign countries and some Indian galleries. Through this, we can also do Video and Audio Chat with the artist watching the exhibition.

In the last two years, I visited many foreign galleries and museums, in which I saw that foreigners in technology were many times ahead of us Indians. The best thing I found is that we cannot see some of the galleries in Foreign without tickets, that means the artist and the gallery are the biggest beneficiaries.

Secondly, I liked that in the museum of Stuttgart (Germany), only the painting of the old masters was seen on the canvas, that is, the color and canvas has become the object of the museum there. Modern-day artists have discovered many modern new mediums by combining technology and art. 
The best example of this was seen in Venice La-Binale (2019), an engineer here who is very sad to make paintings but due to his job he could not give time to his mourning, he made such a machine that creates some patterns and looks like painting, or we can also call it 'robot artist'.

In all these galleries and museums, I got to see very good fusion of technology and culture, that is, we should also explore new techniques through science, by connecting with our Indian culture and discovering new dimensions of art so that our Indian culture is always remain immortal and we will be able to make the future generations aware of Indian culture, because an artist can make technology through art and culture by presenting it to the younger generation with new enthusiasm and can also preserve it. Through this fusion, we will be able to introduce our culture to the next generation in a new way, which will also be exciting for them.

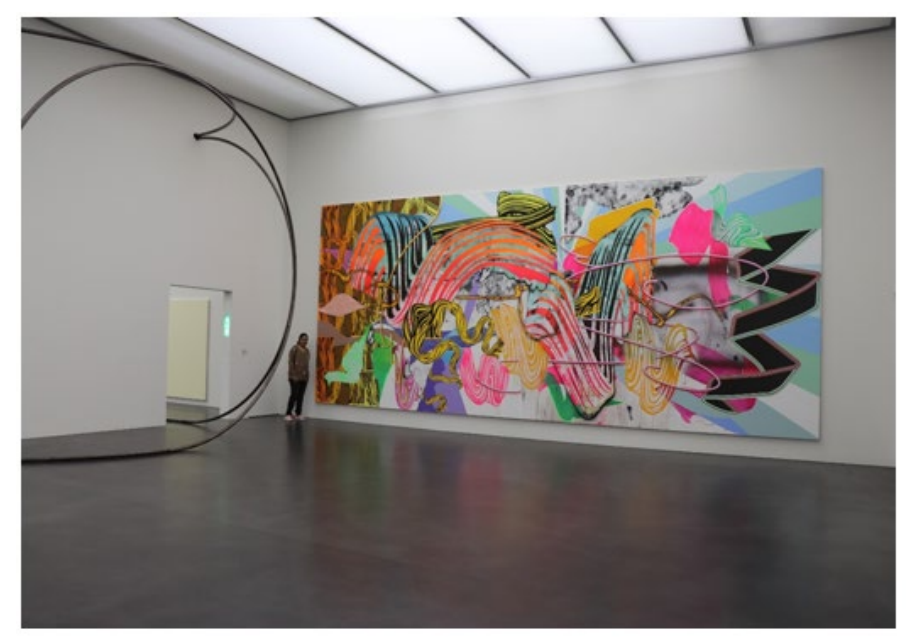

Figure 1 Kunstmuseum Luzern Switzerland

Picture by Author

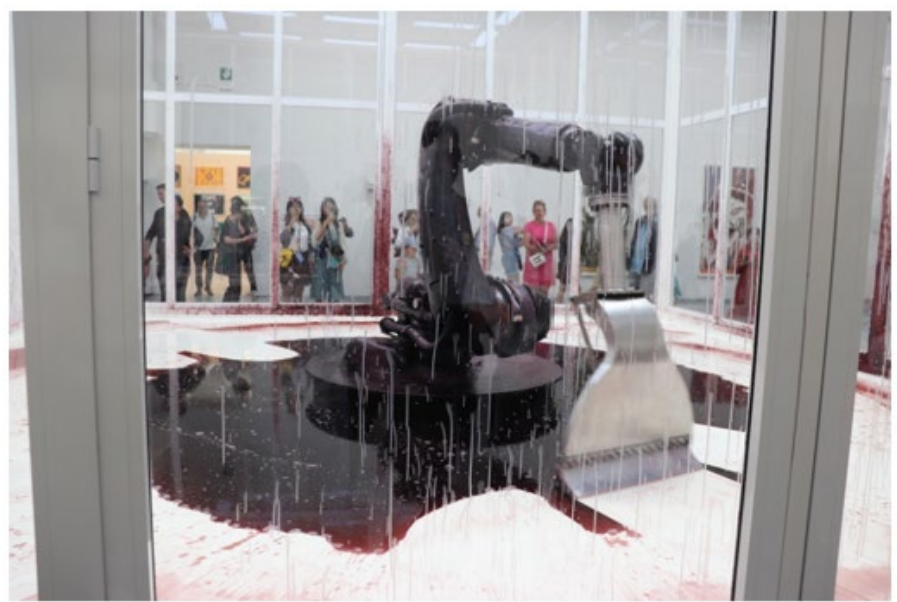

Figure 2 Sun yuan and Peng yu "Can't help myself” robot venice art biennale 2019

Picture by Author 


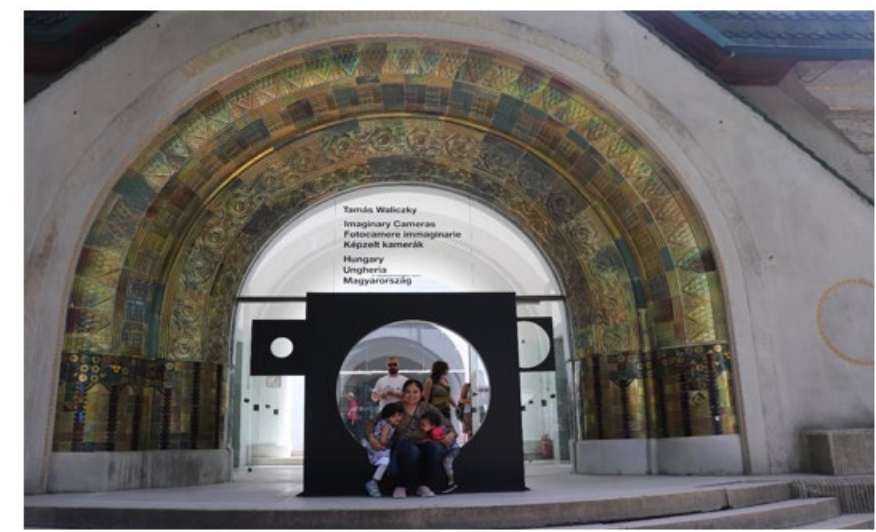

Figure 3 58th Venice Art Biennale 2019 Italy

Picture by Author

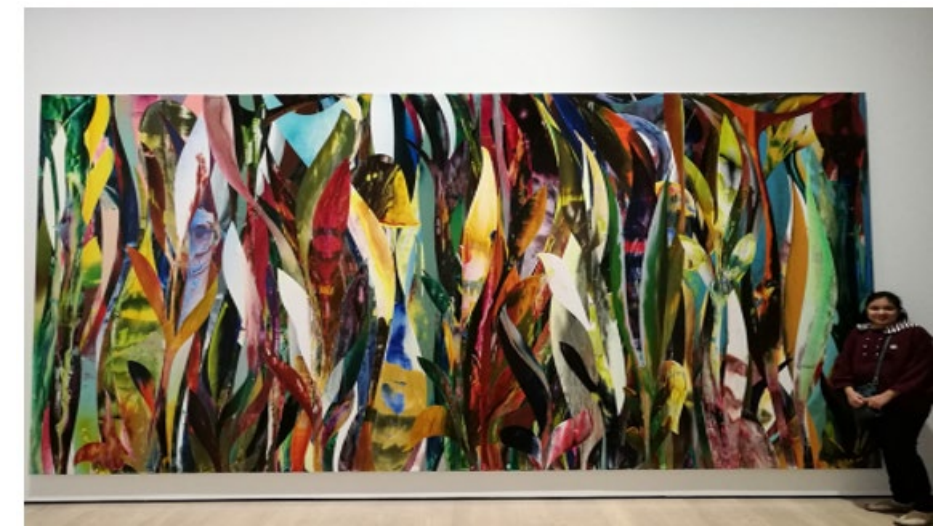

Figure 4 Kunstmuseum Stuttgart is a contemporary and modern art museum in Stuttgart, Germany Picture by Author

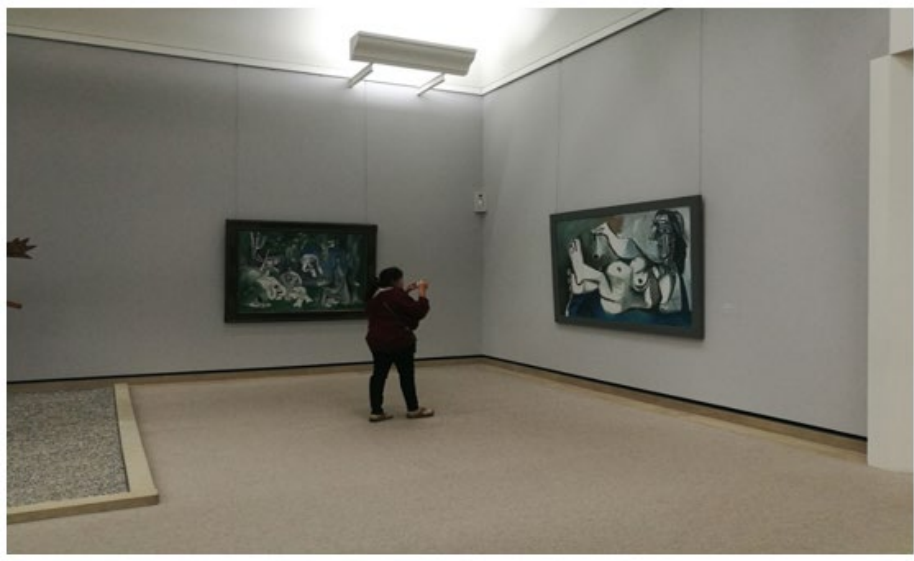

Figure 5 Staatsgalerie Stuttgart, art museum in Stuttgart, Germany Picture by Author 


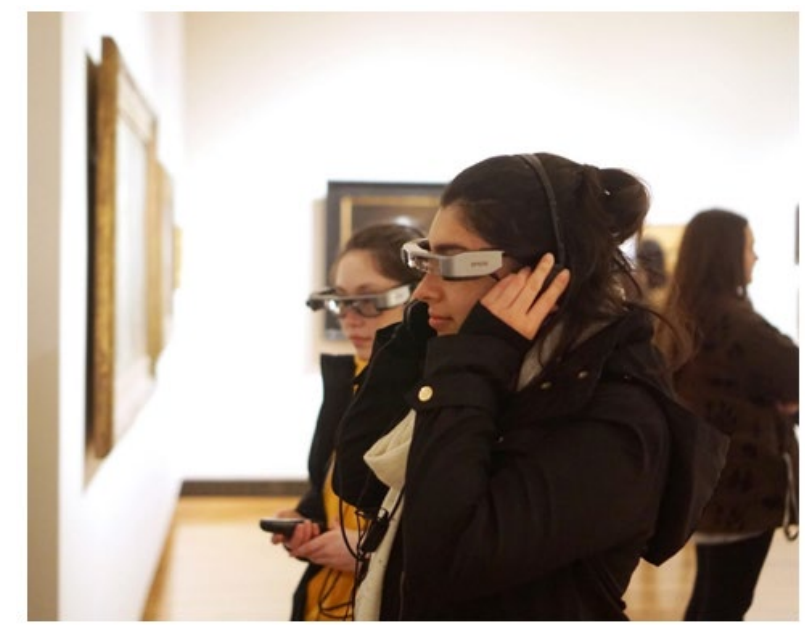

\begin{tabular}{lllllllll}
\hline Figure & 6 & Art & Gallery visitors using Art Glass. Photo courtesy of Art Glass \\
\hline
\end{tabular}

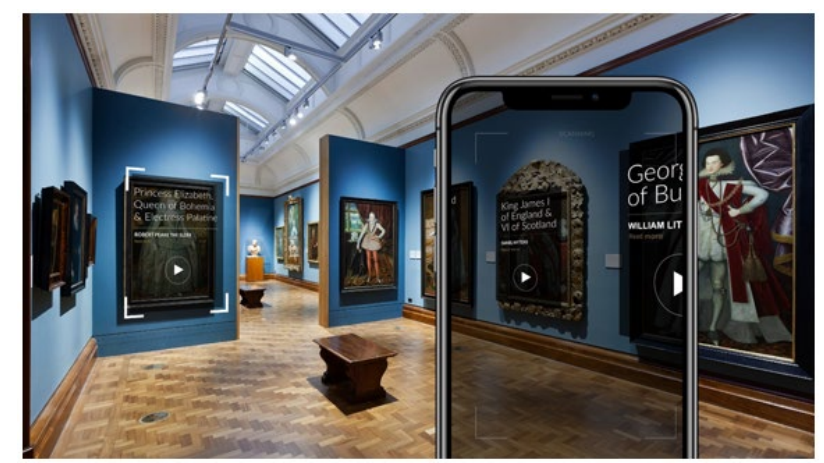

Figure 7 Gallery View of Room 4. "Early Stuart Britain." at The National Portrait Gallery, London, with the Smartify App and its AR technology. Courtesy of Smartify

\section{REFERENCES}

Ashok

Vajpeyi

$(2020$,

April

30),

https://m.facebook.com/story.php?story_fbid=1117498538650159\&id=1 00011700690440

Ashok Vajpeyi (2020, May 03), https://satyagrah.scroll.in/article/135291/kabhikabhar-ashok-vajpeyi-kala-prashishan-aur-sarkar
Birad
Rajaram
Yajnik
$(2020$,
May
04),

https://www.facebook.com/IGNCA/videos/669493906960194/

Dr.

Bharat

Gupt

(2020,

May

https://www.facebook.com/IGNCA/videos/644085243103329/

06),

Malini

Awasthi

(2020,

May

11),

https://www.facebook.com/IGNCA/videos/662158194564149/

Ministry of culture (2020), The Indira Gandhi National Centre for the Arts, https://ignca.gov.in/ 